J Urol. 2017 March ; 197(3 Pt 2): 957-962. doi:10.1016/j.juro.2016.09.109.

\title{
Parental Preference Assessment for Vesicoureteral Reflux Management in Children
}

\author{
Geraldine N. Tran, $\mathrm{BS}^{1}$, Anand V. Bodapati, $\mathrm{PhD}^{2}$, Jonathan C. Routh, MD, $\mathrm{MPH}^{3}$, \\ Christopher S. Saigal, MD ${ }^{4}$, and Hillary L. Copp, MD, MS ${ }^{5}$ \\ ${ }^{1}$ School of Medicine, University of California, San Francisco \\ ${ }^{2}$ Anderson School of Management, University of California, Los Angeles \\ ${ }^{3}$ Division of Urology, Duke University \\ ${ }^{4}$ Department of Urology, University of California, Los Angeles \\ ${ }^{5}$ Department of Urology, University of California, San Francisco
}

\begin{abstract}
Introduction \& objective-Parents of children with vesicoureteral reflux are presented with a variety of management options that in many cases offer a similar risk-benefit ratio. In order to facilitate shared decision-making, parental preferences regarding VUR treatment options need to be acknowledged. This study aims to characterize the clinical experience of parents and elicit core themes affecting decision-making in regards to managing their child's vesicoureteral reflux.
\end{abstract}

Methods-A semi-structured, qualitative interview script was developed and vetted by 25 pediatric urologists to discuss treatment options for VUR. Additional patient interviews were conducted until new themes failed to arise. Content analysis was performed to extract all statements that described treatment options. Similar statements were combined until a final list of unique themes emerged.

Results-Twenty-six interviews were performed yielding 689 statements about parents' overall experiences managing their child's VUR, and $450(65 \%)$ statements pertaining to treatment options. Thirteen themes emerged. Those most commonly considered by parents were: prevention future urinary tract infections (85\%), efficacy rate of treatment options (85\%), burden of daily maintenance or compliance (77\%), antibiotic resistance (69\%), chronic kidney damage (62\%), and invasiveness $(58 \%)$.

Conclusions-Our study emphasizes that when choosing a treatment option for their child's VUR, parents' preferences regarding risks and benefits are variable. However, their chief concerns include whether a method decreases the risk of UTIs, has an acceptable efficacy rate, and aligns itself with their family's capabilities. These themes help frame discussions between families and clinicians regarding VUR management and can facilitate shared decision-making.

Publisher's Disclaimer: This is a PDF file of an unedited manuscript that has been accepted for publication. As a service to our customers we are providing this early version of the manuscript. The manuscript will undergo copyediting, typesetting, and review of the resulting proof before it is published in its final citable form. Please note that during the production process errors may be discovered which could affect the content, and all legal disclaimers that apply to the journal pertain. 


\section{Keywords}

vesico-ureteral reflux/therapy; decision making; patient preference; parents; choice behavior; endoscopy; ureter/surgery; antibiotic prophylaxis; watchful waiting

\section{Introduction and objective}

Parents of children with vesicoureteral reflux (VUR) are presented with a variety of management options, which in many cases offer a similar risk-benefit balance. ${ }^{1,2}$ These options include watchful waiting, antibiotic prophylaxis, endoscopic surgery, open surgery, and laparoscopic/robotic surgery. ${ }^{3}$ Furthermore, the American Urological Association (AUA) VUR guidelines recommend a personalized approach to care that incorporates parental preferences into shared decision-making. ${ }^{4}$ Shared decision-making has been shown to increase patient satisfaction and adherence to therapy, which is particularly applicable to VUR since treatment may require giving daily medications, close monitoring of symptoms, or sensitive post-operative care at home. ${ }^{5,6}$ Although evidence suggests that patients desire involvement in medical decision making, physicians may not reliably understand their preferences. ${ }^{7,8}$ Therefore, it is advantageous to uncover parental values regarding VUR treatment directly from parents in order to formulate evidence-based decisions that also reflect individual needs. This study aims to characterize parental experiences in the clinical care of VUR and to elicit parental preferences regarding VUR treatment options.

\section{Methods}

\section{Study participants}

We retrospectively identified patients of the University of California, San Francisco Benioff Children's Hospitals San Francisco and Oakland who were diagnosed with VUR and have had pursued at least one treatment option for VUR through our electronic medical record (EMR) from 2008 to present. At our institution, patients diagnosed with VUR are treated as per AUA guidelines. ${ }^{4}$ After their initial voiding cystourethrogram (VCUG) and renal ultrasound imaging, we discuss the primary options of observation alone, continuous antibiotic prophylaxis, endoscopic correction, or incisional surgical correction with ureteral reimplantation. Each family is given unbiased written information regarding these options. Each child is then followed on an annual basis with history, physical examination, creatinine, VCUG, and renal ultrasound imaging. We contacted the parents of these patients to serve as interview subjects including some who continue to follow-up for VUR management, and others who their care for VUR. Parents of patients with urologic comorbidities (i.e transplanted kidneys, spina bifida), and for whom English was a secondlanguage were excluded. Participants were offered $\$ 50$ as compensation for their participation.

\section{Data collection}

A semi-structured, qualitative interview script was developed and vetted by 25 pediatric urologists throughout the United States and Canada to discuss reasons for choosing treatment options for VUR with parents. A single pediatric urologist (HC) conducted 
telephone interviews with consented parents of pediatric patients treated for VUR. Table 1 gives examples of open-ended and directed questions asked during the interviews (Supplemental). The treatment options presented to parents were watchful waiting, antibiotic prophylaxis, endoscopic surgery with dextranomer/hyaluronic acid copolymer, and ureteral reimplantation open surgery. Generally, the interviews lasted 30-45 minutes covering reasoning for choosing a treatment option, concerns about certain treatments, and the barriers to compliance. Parents were recruited and interviews conducted until new themes failed to arise from additional participants (Supplemental Table 1). Interviews were transcribed verbatim by an automated third party service. Our institution's internal review board and human research protection program approved the collection and use of data for our study.

\section{Analysis}

We performed a content analysis of interview transcripts to extract all statements pertaining to treatment options for VUR. The goal of the content analysis was to systematically identify statements and opinions shared by parents and to condense them into common themes. The interview transcripts were first deconstructed into individual statements, and statements unrelated to VUR treatment options were eliminated. Two researchers independently coded parents' treatment-related statements by themes expressing distinct preferences (GT, HC). Themes represent topics commonly addressed and can encompass varying points of view. For example, the theme "cosmetically damaging outcome" represents statements expressing high and low concern for scarring. Similar themes were combined until a final list of higherorder themes emerged. Disputes regarding assigning and merging themes were resolved through discussion with a six-member expert panel. This panel consisted of the authors and one additional collaborator, all of who contributed their respective experience in qualitative research, outcomes research, preference assessment studies, and pediatric urology. This process has been extensively described in prior studies. ${ }^{9-11}$

\section{Results}

Overall, 26 parents representing an equal number of VUR patients, were interviewed. Our enrollment number compares with similar qualitative studies, which interviewed 17-18 individuals. ${ }^{11,12}$ Qualitative studies' sample sizes are typically much smaller than for quantitative studies because we need just one occurrence of each common construct. The median age of patients at initial VUR consultation was 18 months (IQR 10-36). Ten patients (39\%) were male, $13(50 \%)$ exhibited bilateral reflux, and 5 (20\%) had a duplicated system. Six (24\%) had VUR Grade 1-2, and 19 (76\%) had Grade 3-5. Also, 10 (40\%) exhibited bladder and bowel dysfunction and $22(85 \%)$ presented with a urinary tract infection (UTI). Regarding management options for VUR, 8 parents chose watchful waiting, 25 chose antibiotic prophylaxis, 3 chose endoscopic surgery, and 9 decided on open surgery for their child's VUR (Table 2).

Among interviewed parents, demographic data was available for 19 of 26 subjects (73\%). Their median age at interview was 37 years (IQR 29-43); 17 (90\%) were mothers, and 15 
(79\%) parents were in a relationship. 11 (58\%) parents were employed full-time, and 11 $(58 \%)$ had obtained a college or higher level of education (Table 3 ).

The interviews yielded 689 statements about the parents' overall experiences managing their child's VUR, and 450 (69\%) statements differentiating the treatment options. Our analysis determined 13 major themes influencing parental decision-making when considering a management option for VUR. Table 4 lists each theme with an example quote directly from our interviews.

\section{Prevention of future urinary tract infections}

This theme reflects the ability of a treatment option to actively lower the risk of future urinary tract infections (UTIs) in addition to maintaining adequate bowel and bladder function. $85 \%$ of parents considered preventing future UTIs for their child. Treatment options that provide prevention of future UTIs include antibiotic prophylaxis, endoscopic surgery, and open surgery. Parents expressed desire to combat UTIs due to the symptoms their children experienced. Oftentimes, this theme was their major priority when considering a management option.

\section{Efficacy rate}

Efficacy rate was defined by the rate of reflux resolution offered by a management option immediately after initiation. Watchful waiting and antibiotic resistance do not correct reflux, while endoscopic surgery and open surgery do so for $80 \%$ and $95 \%$ of cases, respectively. 13-15 $85 \%$ of parents considered the various efficacy rates while choosing a management option. Also, parents expressed concern over the risk of a second operation after an endoscopic procedure. In general, parents favored a treatment option with the highest chance of fixing reflux.

\section{Burden of daily maintenance}

This trait refers to the necessary tasks placed on the family for compliance with a treatment option. 77\% of parents considered the burden of daily maintenance. Parents considered transportation, giving a medication daily, monitoring for symptoms constantly, and handling post-operative care at home. This theme reflects the importance of coming to personalized decisions for families as parents possessed differing opinions about the difficulty of compliance for a certain management option. For example, while one parent may view giving a medication daily for years as the most burdensome task, another may see the issue as trivial compared to a hospital stay and post-operative care.

\section{Antibiotic resistance}

$69 \%$ of parents considered whether or not a treatment option could cause antibiotic resistance to future infections. Antibiotic prophylaxis for VUR has been shown to increase bacterial resistance to trimethoprim-sulfamethoxazole compared with placebo. ${ }^{16}$ 


\section{Chronic kidney damage (CKD)}

Preventing CKD, which parents understood to include renal scarring and hypertension requiring medications, was a concern for $69 \%$ of parents. Watchful waiting may increase the risk of CKD, while other treatment options take action to prevent such consequences. ${ }^{17,} 18$

\section{Feeling of taking action}

This theme illustrates the desire to select a treatment that actively combats reflux and its symptoms. Parents considered whether or not a treatment option gave them the feeling of being proactive and ready to take necessary steps. $62 \%$ of parents considered whether or not they desired to take action. Parents felt that antibiotics, endoscopic surgery, and open surgery allowed them to take action for their child.

\section{Invasiveness}

This theme illustrates how conservative a treatment was with watchful waiting being the least invasive, and open surgery the most invasive. 58\% of parents considered the degree of invasiveness required for each treatment option.

\section{Anesthesia requirement}

$50 \%$ of parents considered whether or not a treatment option required anesthesia, and if so, then the duration of anesthesia administration.

\section{Possibility of overtreatment}

$46 \%$ of parents considered whether a treatment option allowed the possibly for VUR to correct naturally without definitive treatment. Surgical options were presented as options that would thwart spontaneous resolution of reflux.

\section{VCU after initiation of management}

$46 \%$ of parents considered whether or not a VCUG was needed after starting a management option. The concerns surrounding VCUG consisted not only of perceived pain and discomfort for their child, but parents were also keen to avoid their own emotional stress from watching their child resist catheterization and be restrained for imaging. Radiation exposure was also a reason to avoid VCUGs after treatment.

\section{Psychological stress on child}

$46 \%$ of parents considered the degree of perceived emotional stress on their child due to the necessary components of each treatment option. Examples of perceived psychological stress that parents preferred to avoid for their child included anxiety at doctor visits, staying in the hospital, fear of invasive diagnostic procedures, and discomfort surrounding urination.

\section{Burden of contact with healthcare professionals or setting}

$35 \%$ of parents considered the amount of time spent within healthcare settings or professionals required by each treatment option. For example, watchful waiting and antibiotic prophylaxis would require families to bring their child to their urologist annually over years, while surgical options would require a hospital stay, but then few visits onwards. 
The opinions regarding contact with healthcare varied among parents. Some parents preferred frequent clinic visits without a hospital stay, while others preferred a hospital stay without frequent clinic visits.

\section{Cosmetically damaging outcome}

$19 \%$ of parents considered whether or not a treatment option left a scar on their child's body. Although this was the least commonly expressed theme, parents weighed scarring when deciding between endoscopic and open surgery.

\section{Discussion}

Our study elicited thirteen important themes that parents consider when deciding on a treatment option for their child's VUR. Their most common concerns included decreasing the risk of UTIs, the efficacy rates, and the burdens on compliance. Along with endorsing parental preferences elicited by prior studies, our results add themes unrecognized in the current literature such as burden of compliance, CKD, feeling of taking action, anesthesia requirement, possibility of overtreatment, and psychological stressors on a child. While there are reports examining parental decision-making with VUR, they utilized structured surveys that do not allow new preferences to emerge. Our study adds valuable information elicited through a mixed-methods qualitative approach that systematically derived key factors affecting decision-making.

In 2001, Ogan et al. completed the first published study looking at parental preferences regarding VUR. They determined that most parents would choose antibiotics over surgical correction if reflux were likely to persist to four years, and that $60 \%$ of parents favored endoscopic over incisional surgery. ${ }^{19}$ More recently, Krill et al. also found that parents preferred surgery if longer follow-up times would ensue. ${ }^{20}$ Furthermore, in 2003, Capozza et al. claimed that parents specifically favored endoscopic treatment, and that such an option should be the first-line therapy for persistent grade III reflux. ${ }^{21}$ Likewise, our study elicited the importance of invasiveness, with many parents preferring a stepwise approach from watchful waiting or antibiotics to a surgical solution. In general weighed invasiveness against the effectiveness of a treatment option to fix reflux. For example, the chance of returning for a second or third endoscopic procedure was less enticing to some parents than a single open surgery.

In more recent years, Callaghan et al. determined that including invasiveness, most important factors to parents were success rates and the need for post-operative VCUG. ${ }^{22}$ This study looked at surgical cases only. In comparison, our study considers surveillance, medical, and surgical treatment options. Through interviewing parents and allowing for open dialogue, our approach also found success rates and the necessity of a VCUG as important factors parents consider in making a decision for their child. However, they were not the most commonly expressed theme, falling well behind themes such as the ability of a treatment option to reduce UTI recurrence and the burden of daily maintenance.

Hsieh et al. determined that race and income may influence parental decision-making, but that the treating urologist's opinion was highly valued by parents regardless of 
socioeconomic factors. ${ }^{23}$ Although this highlights how clinicians can impact decisionmaking and the opportunity for improving shared decision-making, this study did not differentiate between treatment options. Considering our themes allows patients and clinicians to select the appropriate treatment option based on parental preferences. For example, a treatment option that requires giving your child a medication daily and is less invasive would reflect antibiotic prophylaxis.

Due to the rate of spontaneous resolution of reflux, watchful waiting has become an accepted management option if parents choose to diligently monitor their child for UTIs. ${ }^{24}$ The first qualitative study incorporating watchful waiting found that satisfaction was not statistically different between parents who chose conservative management versus endoscopic surgery. This study also noted that febrile UTI recurrence and kidney scarring did not influence parental satisfaction. ${ }^{25}$ However in our study, we found that most parents considered the possibility of eliminating UTIs and CKD when choosing a management option. Our study highlights that treatment choices may be individualized for each family and child with VUR.

Although adding needed information, our study has certain limitations. Our study collected demographic and clinical characteristics on our patients and parents in a retrospective fashion. Thus information not captured by EMR or phone interviews was irretrievable. We interviewed parents who had already gone through VUR management for their child, and therefore they are subject to recall bias. It is possible that parents who are considering VUR treatment options for the first time may have additional preferences. Also, the majority of interviewed parents were Caucasian mothers. Different parenting roles and cultural backgrounds may influence responses from parents. Moreover, by personally interviewing patients over telephone, we were able to conduct semi-structured conversations. However, unlike a validated survey, such a format can vary between participants. Also, telephone communication restricted us from responding to body language that might alert us to a subject's hesitation in identifying a construct as important. With these themes uncovered, further studies may structure them into a quantifiable survey for uniform data acquisition.

\section{Conclusion}

Our study emphasizes that when faced with choosing a treatment option for their child's VUR, parents have variable preferences regarding risks and benefits. Parents' chief concerns include eliminating future urinary tract infections, the efficacy rate, and burdens placed on their families. These themes may provide a framework for shared decision-making and can form the basis for a clinical tool matching available treatment options for VUR with key parental preferences.

\section{Supplementary Material}

Refer to Web version on PubMed Central for supplementary material. 


\section{Acknowledgments}

Dr. Copp was supported by the University of California, San Francisco KURe Career Development Program (National Institutes of Health grant 1-K12-DK-083021), and Dr. Routh was supported by grant K08-DK100534. The sponsors did not have any role in the design or conduct of the study, analysis of data, or drafting of the manuscript.

The authors are grateful for the contribution of Sylvia Lambrechts for insights on selecting themes and participating as a member of our expert panel. The authors would like to thank the following people for their critical review of the semi-structured, qualitative interview script designed to discuss treatment options for VUR with parents: Laurence Baskin, Sisir Botta, Luis Braga, Anthony Caldamone, Christopher Cooper, Ross Decter, Michael Disandro, John Gatti, Anthony Herndon, Barry Kogan, Armando Lorenzo, Craig Peters, Alexandra Quittner, Esequiel Rodriquez, Kara Saperston, Bruce Schlomer, Ronald Sutherland, Stacy Tanaka, Gregory Tasian, Dana Weiss, Elizabeth Yerkes, and Jenny Yiee.

\section{Key Standard abbreviations}

$\begin{array}{ll}\text { VUR } & \text { Vesicoureteral reflux } \\ \text { AUA } & \text { American Urologic Association } \\ \text { EMR } & \text { Electronic medical record } \\ \text { VCUG } & \text { Voiding cystourethrogram } \\ \text { UTIs } & \text { Urinary tract infections } \\ \text { CKD } & \text { Chronic kidney disease }\end{array}$

\section{References}

1. Nagler EV, Williams G, Hodson EM, et al. Interventions for primary vesicoureteric reflux. Cochrane Database Syst Rev. 2011; (6):CD001532. CD001532. [PubMed: 21678334]

2. Wheeler D, Vimalachandra D, Hodson EM, et al. Antibiotics and surgery for vesicoureteric reflux: a meta-analysis of randomised controlled trials. Arch Dis Child. 2003; 88:688. [PubMed: 12876164]

3. Lopez PJ, Celis S, Reed F, et al. Vesicoureteral reflux: current management in children. Curr Urol Rep. 2014; 15:447. [PubMed: 25217412]

4. Peters CA, Skoog SJ, Arant BS Jr, et al. Summary of the AUA Guideline on Management of Primary Vesicoureteral Reflux in Children. J Urol. 2010; 184:1134. [PubMed: 20650499]

5. Speedling EJ, Rose DN. Building an effective doctor-patient relationship: from patient satisfaction to patient participation. Soc Sci Med. 1985; 21:115. [PubMed: 4048997]

6. Loh A, Leonhart R, Wills CE, et al. The impact of patient participation on adherence and clinical outcome in primary care of depression. Patient Educ Couns. 2007; 65:69. [PubMed: 17141112]

7. Bruera E, Willey JS, Palmer JL, et al. Treatment decisions for breast carcinoma: patient preferences and physician perceptions. Cancer. 2002; 94:2076. [PubMed: 11932912]

8. Janz NK, Wren PA, Copeland LA, et al. Patient-physician concordance: preferences, perceptions, and factors influencing the breast cancer surgical decision. J Clin Oncol. 2004; 22:3091. [PubMed: 15284259]

9. Burchill, G., Hepner Brodie, C. Center for Quality Improvement (Cambridge, Mass.). Voices into choices: acting on the voice of the customer. Madison, Wisconsin: Oriel Inc; 2005.

10. Griffin A, Hauser JR. The Voice of the Customer. Marketing Science. 1993; 12:1.

11. Dahan, Ely, Lambrechts, Sylvia, Saigal, Christopher. The Voice of the Patient. Proceedings of the Sawtooth Software Conference. 2012:153.

12. Harrison JD, Logar T, Le P, et al. What Are the Ethical Issues Facing Global-Health Trainees Working Overseas? A Multi-Professional Qualitative Study. Healthcare (Basel). 2016; 4doi: 10.3390/healthcare4030043 
13. Garcia-Aparicio L, Rovira J, Blazquez-Gomez E, et al. Randomized clinical trial comparing endoscopic treatment with dextranomer hyaluronic acid copolymer and Cohen's ureteral reimplantation for vesicoureteral reflux: long-term results. J Pediatr Urol. 2013; 9:483. [PubMed: 23602843]

14. Holmdahl G, Brandstrom P, Lackgren G, et al. The Swedish reflux trial in children: II. Vesicoureteral reflux outcome. J Urol. 2010; 184:280. [PubMed: 20488469]

15. Routh JC, Inman BA, Reinberg Y. Dextranomer/hyaluronic acid for pediatric vesicoureteral reflux: systematic review. Pediatrics. 2010; 125:1010. [PubMed: 20368325]

16. Hoberman A, Greenfield SP, et al. RIVUR Trial Investigators. Antimicrobial prophylaxis for children with vesicoureteral reflux. N Engl J Med. 2014; 370:2367. [PubMed: 24795142]

17. Brandstrom P, Neveus T, Sixt R, et al. The Swedish reflux trial in children: IV. Renal damage J Urol. 2010; 184:292. [PubMed: 20494369]

18. Faust WC, Diaz M, Pohl HG. Incidence of post-pyelonephritic renal scarring: a meta-analysis of the dimercapto-succinic acid literature. J Urol. 2009; 181:290. [PubMed: 19013606]

19. Ogan K, Pohl HG, Carlson D, et al. Parental preferences in the management of vesicoureteral reflux. J Urol. 2001; 166:240. [PubMed: 11435878]

20. Krill AJ, Pohl HG, Belman AB, et al. Parental preferences in the management of vesicoureteral reflux. J Urol. 2011; 186:2040. [PubMed: 21944107]

21. Capozza N, Lais A, Matarazzo E, et al. Treatment of vesico-ureteric reflux: a new algorithm based on parental preference. BJU Int. 2003; 92:285. [PubMed: 12887485]

22. Callaghan K, Gray E, Caldamone A, et al. Factors involved in parental decision making for surgical correction of vesicoureteral reflux. J Urol. 2008; 180:701. [PubMed: 18554643]

23. Hsieh MH, Madden-Fuentes RJ, Bayne A, et al. Cross-sectional evaluation of parental decision making factors for vesicoureteral reflux management in children. J Urol. 2010; 184:1589. [PubMed: 20728107]

24. Knudson MJ, Austin JC, McMillan ZM, et al. Predictive factors of early spontaneous resolution in children with primary vesicoureteral reflux. J Urol. 2007; 178:1684. [PubMed: 17707023]

25. Neveus T, Brandstrom P, Linner T, et al. Parental experiences and preferences regarding the treatment of vesicoureteral reflux. Scand J Urol Nephrol. 2012; 46:26. [PubMed: 22008041] 


\section{Table 1}

Example questions from semi-structured interview done with parents of pediatric vesicoureteral reflux patients.

\section{Diagnostics}

Tell me about your experience with the study (VCUG) used to diagnose reflux?

What things did you think about or consider when your child had imaging done?

What were your thoughts, considerations, or concerns about the VCUG?

Did having to repeat this study every 1-2 years influence your decision?

Treatment options

What were your thoughts, considerations, or concerns about watchful waiting/antibiotic prophylaxis/endoscopic surgery/open surgery?

Why did or did you not choose watchful waiting/antibiotic prophylaxis/endoscopic surgery/open surgery?

Ultimately what were the main factors that influenced your decision to have your child undergo/not undergo watchful waiting/antibiotic

prophylaxis/endoscopic surgery/open surgery?

General sentiments about VUR

Would it bother you if your child continued to have reflux but no infections and we stopped following your child?

Overall what were your biggest concerns about your child having VUR?

Do you feel like the goals of treatment were accomplished? 
Table 2

Clinical characteristics of patients with vesicoureteral reflux.

\begin{tabular}{|ll|}
\hline Characteristics & $\mathbf{N}(\%)$ \\
\hline Overall (n=26) & 18 (IQR 10-36) \\
\hline Age at initial VUR visit (months) & $10(39)$ \\
\hline Male & 29 (IQR 20-44) \\
\hline Length of follow-up (median in months) & $6(24)$ \\
\hline Grade & $19(76)$ \\
\hline VUR grade 1-2 & $13(50)$ \\
\hline Bilateral reflux & $5(20)$ \\
\hline $\begin{array}{l}\text { Duplicated system } \\
\text { Bladder and bowel dysfunction }\end{array}$ & $10(40)$ \\
\hline Treatment choice * & 8 \\
Watchful waiting & $22(85)$ \\
Antibiotic prophylaxis & 3 \\
Ondoscopic surgery & 9 \\
\hline Presentation with UTI yes/no & 25 \\
\hline
\end{tabular}

Treatment choices sum to $>100 \%$ because $>1$ treatment option could have been selected for each patient 
Table 3

Demographics of parent participants at the time of interviews.

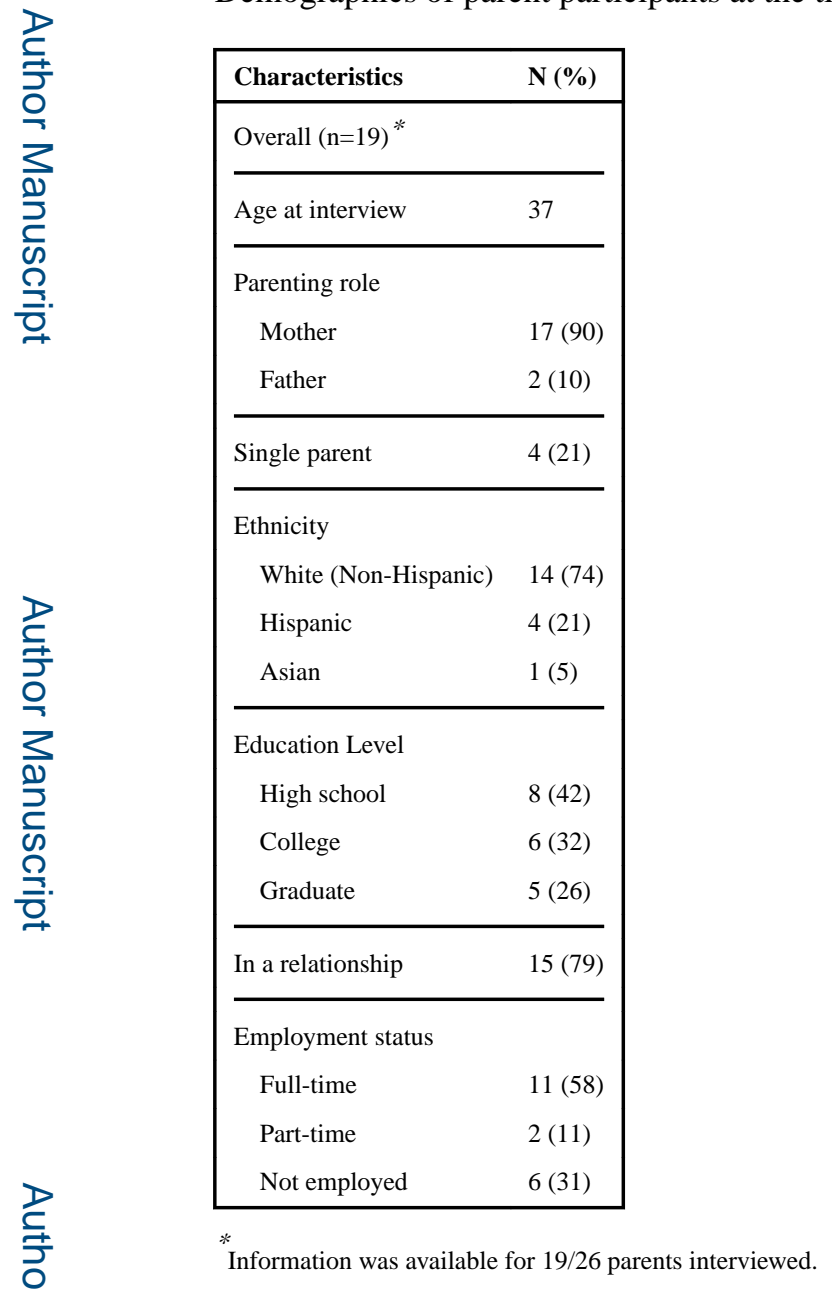


Table 4

Themes and quotes representing parents' concerns when deciding on a management option for their child's vesicoureteral reflux.

\begin{tabular}{|c|c|c|c|}
\hline Theme & Example quote & $\begin{array}{l}\text { Number of } \\
\text { parents } \\
\text { who } \\
\text { expressed } \\
\text { concern }\end{array}$ & $\begin{array}{l}\text { \% of parents } \\
\text { interviewed }\end{array}$ \\
\hline Prevention of future UTIs & $\begin{array}{l}\text { "My biggest concerns with her having reflux were the risk of } \\
\text { another kidney infection to where she would get sick, and the ones } \\
\text { that she had because she was too young to tell me - that's why we } \\
\text { decided to do the antibiotics." }\end{array}$ & 22 & 85 \\
\hline Efficacy rate & $\begin{array}{l}\text { "The fact that it has a lower success rate and that you might have to } \\
\text { repeat it. That would bother me." }\end{array}$ & 22 & 85 \\
\hline Burden of daily maintenance & $\begin{array}{l}\text { “...when you live far away, it's kind of a drive and hard } \\
\text { transportation-wise getting out there--and that's traveling back and } \\
\text { forth.” }\end{array}$ & 20 & 77 \\
\hline Antibiotic resistance & $\begin{array}{l}\text { "There could be a time when she really needs an antibiotic for } \\
\text { something else and then she's developed immunity to all these } \\
\text { antibiotics." }\end{array}$ & 18 & 69 \\
\hline Chronic kidney damage & $\begin{array}{l}\text { "We went on it preventatively, so that we wouldn't have long-term } \\
\text { kidney damage." }\end{array}$ & 16 & 62 \\
\hline Feeling of taking action & $\begin{array}{l}\text { "My husband and I felt very strongly about [doing] the surgery and } \\
\text { just being done with it for her because it was a long [time]." }\end{array}$ & 16 & 62 \\
\hline Invasiveness & $\begin{array}{l}\text { "I would have probably been most comfortable with watchful } \\
\text { waiting, then go on the prophylactic, and then sort of like a slow } \\
\text { increment rather than say okay, surgery right away." }\end{array}$ & 15 & 58 \\
\hline Anesthesia requirement & $\begin{array}{l}\text { "Going under general, there's no guarantee. There's always that } \\
\text { chance, that possibility of the patient not waking up." }\end{array}$ & 13 & 50 \\
\hline Possibility of overtreatment & $\begin{array}{l}\text { "We wanted her body to have a chance to try to see if it would fix } \\
\text { itself, even though it was a small percentage." }\end{array}$ & 12 & 46 \\
\hline $\begin{array}{l}\text { VCUG after initiation of } \\
\text { management }\end{array}$ & $\begin{array}{l}\text { "...I would not want to continually do the dye study over and over } \\
\text { again." }\end{array}$ & 12 & 46 \\
\hline Psychological stress on child & $\begin{array}{l}\text { "She couldn't hold her urine in anymore. And then she has to } \\
\text { urinate in a diaper. I think she felt almost like it was demeaning to } \\
\text { her." }\end{array}$ & 10 & 39 \\
\hline $\begin{array}{l}\text { Burden of contact with healthcare } \\
\text { professionals or setting }\end{array}$ & $\begin{array}{l}\text { "Would there be follow-ups, and would it be continual? Would it } \\
\text { be something that could be resolved in one shot?" } \\
\text { "I prefer the hospital stay. I wish it would be longer personally } \\
\text { because I feel the more professionals watching over my child after } \\
\text { they open her up, the better because the doctors and the nurses } \\
\text { know more than I do. So for me, I'd rather have her stay in there a } \\
\text { week just to see that she was perfect and then take her home." }\end{array}$ & 9 & 35 \\
\hline Cosmetically damaging outcome & $\begin{array}{l}\text { "I don't want to sound shallow but I just don't want her to have to } \\
\text { have a big old scar on her body." }\end{array}$ & 5 & 19 \\
\hline
\end{tabular}

